\title{
A review of pressure measurement on the contact surface between the horse and the rider
}

\author{
Miroslav Janura', Lee Cabell, Zdenek Svoboda', Tereza Dvorakova', Eva Haltmayer ${ }^{3}$ and Eva Janurova ${ }^{4}$ \\ Department of Natural Sciences in Kinanthropology, Faculty of Physical Culture, Palacky University Olomouc, Olomouc, Czech Republic ${ }^{1}$, Department of Gra- \\ duate Programs in Health Sciences, School of Health and Medical Sciences, Seton Hall University, South Orange, NJ, U.S.A. ${ }^{2}$, Clinic for Orthopaedics in Ungu- \\ lates, University of Veterinary Medicine Vienna, Vienna, Austria ${ }^{3}$ and Institute of Physics, Faculty of Mining and Geology, VSB-Technical University of Ostrava, \\ Czech Republic ${ }^{4}$
}

\begin{abstract}
Summary
The use of systems for pressure measurement between the rider's body and the back of the horse is a relatively new procedure. The size and transfer of the load inside the horse-pad-saddle-rider system can be assessed in various ways. This paper provides a review of literature published from 1994 to 2010 that discusses using pressure mapping systems for measuring the contact load between the horse and its rider. Literature was obtained using common scientific databases such as Web of Science, SCOPUS and PubMed entering the key words: "horse", "pressure", and "back". The first published studies aimed to verify sensor parameters and to minimize animal-and operator-induced errors. In order to obtain valid and reliable data, it is important to perform pressure measurements under highly standardized conditions. Moreover using properly established guidelines for calibrating and placing sensors is crucial for receiving valid data. Subsequent studies focused on the influence of various types of saddles, pads, blankets and adjustments of saddle fit on the loading of the horse's back. Results of these studies showed that using pressure mapping systems provide a useful evaluation of the load applied to the area of contact between the horse and rider. A properly fitted saddle with a pad can serve as a shock absorber. Literature findings suggest that improving the fit of a saddle by using a saddle pad needs to be individually adapted for each horse and rider. Considering the current status of literature on the use of pressure mapping systems in horseback riding future research should concentrate on using data obtained by biomechanical modelling of contact surfaces, including their interactions; on determining a "normal pattern" of pressure distribution on the equine back; and on finding a way to include individual parameters of the horse and its rider into the overall assessment.
\end{abstract}

Keywords: Horseback riding / horse / back / rider / pressure / saddle / pad / measurement

\section{Druckmessungen an den Kontaktflächen zwischen Pferd und Reiter - eine Literaturübersicht}

Die Größe und die Einwirkung der Belastung im System Pferd - Unterlage - Sattel - Reiter muss aus verschiedenen Blickwinkeln betrachtet werden. Diese Arbeit präsentiert eine Übersicht die Anwendung von Drucksystemen zur Messung der Kontaktbelastungen zwischen Pferd und Reiter. Die Auswahl der Studien erfolgte unter Verwendung der Suchbegriffe "horse", "pressure " und "back" in den Datenbanken Web of Science, Scopus und PubMed. Im ersten Teil dieses Artikels werden Studien präsentiert, die sich mit der die Entwicklung von Druckmesssystemen für den Reitsattel beschäftigen. Der erste, notwendige Schritt vor der Anwendung dieser Druckmesssysteme ist die Überprüfung der Parameter, um etwaige Fehlerquelle festzustellen und so Bedienungsfehler ausschließen zu können. Um zuverlässige und gültige Daten zu erhalten, müssen methodische Regeln (wie z. B.: korrekte Kalibrierung und korrekte Sensor-Platzierung) eingehalten werden. Im nächsten Teil dieses Artikels wird Betonung auf die Beurteilung der biologischen Systeme (Reiter, Pferd) und deren Interaktion mit dem Sattel als rigide Struktur gelegt. Es werden erste wissenschaftliche Studien, die Druckmessungen beim Reiten, bei unterschiedlichen Sätteln, Sattelkissen, Satteldecken und Änderungen, die durch verschiedene Sattelpolsterungen verursacht werden, untersuchen, diskutiert. Ein schlecht aufliegender Sattel ist ein Grund für Rückenschmerzen, die zur Senkung der Lebensqualität und der Rittigkeit des Pferdes führen. Die Stabilität des Reitersitzes kann mit Hilfe des Druckmesssystem quantifiziert werden. Sie ist für die Kommunikation zwischen Reiter und Pferd wichtig. Von gleicher Bedeutung ist auch Einfluss des Reiters auf die Belastung. Um das Verständnis verschiedener Einflüsse auf Ätiologie und Pathogenese des Pferderückens zu erhöhen, können biomechanische Modelle zur dynamischen Simulation verwendet warden. Auch zur Dokumentation von Hippotherapie ist der Einsatz des Druckmesssystems vorteilhaft. Eine Zunahme der Gesamtkraft zwischen Patient und Pferderücken drückt erhöhtes Selbstvertrauen (Sicherheit) des Reiters aus. Dies ist eine der positiven Wirkungen der Therapie. Aus den Ergebnissen der im Review diskutierten Studien geht hervor, dass die Anwendung der Druckmesssysteme zur Bewertung der Belastung des Pferderückens und des Reiters Bedeutung hat. Zukünftige Forschung sollte sich auf die Einbindung der gesammelten Daten in biomechanische Modelle konzentrieren, umso individuelle Interaktionsmuster besser abgrenzen zu können.

Schlüsselwörter: Reiten / Pferd / Rücken / Reiter / Druck / Sattel / Unterlage / Messung

\section{Introduction}

The interaction between two biological systems with a large variability is typical for horseback riding, as well as for hippotherapy. Understanding the properties of each of these systems is a very important tool for assessing the rider-horse interaction (Schöllhorn et al. 2006). The harmony that can be achieved between horse and rider depends on both participating individuals (Peham et al. 2004), as well as on the equipment or on the lack of the latter, respectively that creates an interface between those individuals.

The horse-pad-saddle-rider system includes a various number of different variables considering the system's characteristics and setup. All of these variables influence the size and transfer of the load on the contact surface between the rider's body and the horse's back (Wesley 2006). The aim of this study was to provide readers with information about systems for 
pressure measurement between a horse and its rider. Additionally in order to obtain valid data suitable methods and guidelines for applying those systems were assessed.

Further, this article aims to identify factors that can influence measured values and therefore make it harder to compare data obtained in different studies. On the basis of these studies this current article discusses how these measurement systems can be used in horseback riding and hippotherapy. Moreover this study suggests issues and topics for further research.

\section{Search strategy}

The search was performed in Web of Science, SCOPUS and PubMed databases using "horse," "pressure," and "back" as key words. Only peer-reviewed journals, reviews, and contributions to conferences published from 1990-2011 were chosen for further review. Out of 111 studies found, 24 matched the inclusion criteria for our review study. Additionally, citations were searched and tracking of reference lists was performed. There were no language restrictions and non-English papers were translated when necessary. Unfortunately so far not many studies have been performed dealing with pressure measurement in horseback riding. Therefore this review was carried out as an overview study, which does not include some typical elements of a critical review. Methodological aspects of selected studies included in this review are summarized in Table 1.

\section{Use of systems for measuring pressure in horseback riding}

Instrumentation

The use of pressure sensors (mapping systems) is common in biomechanical applications. The first studies in this field published in the 1970s and 1980s were performed for the automotive industry (improvement of seating comfort) and for health care (dental occlusion, footwear, wheelchair seat mapping) (Garber et al. 1978, Krouskop et al. 1983, FergussonPell et al. 1985). Harman (1994) first used a pressure measurement system for evaluation of interactions between horse and rider (saddle) about 10 years later. In the earlier studies, the systems used were custom made for the purpose of pressure measurements on the horse's back (Harman 1997). In the current studies, the most common systems used are two commercially manufactured systems: Pliance System (Novel $\mathrm{GmbH}$, München, Germany), used to measure pressures with two pressure mats containing 224 (256) sensors of size $2.5 \mathrm{x}$ $3.2 \mathrm{~cm}$; and Force Sensing Array (FSA) technology (VERG, Inc., Winnipeg, Canada), with 256 sensors of varying sizes. The characteristics and parameters of the measuring sensors highly influence the quality of measured data.

The essential requirements for human interface measurement sensors are linearity, low hysteresis, low creep, low temperature sensitivity, flexibility, thin construction, large range of measurement, and reliability (Fergusson-Pell et al. 1976). All these parameters have to be considered in the development of a pressure measurement systems used in horseback riding.
The quality and parameters of sensors have improved with the development of new technologies. Therefore, the studies using modern measurement systems are usually just influenced by animal- and operator-induced errors.

The validity and reliability of the particular measuring system plays a key role when using these devices to evaluate interactions between horse and rider. Jeffcott et al. (1999) evaluated the accuracy and reliability of the FSA technology by performing pressure measurements beneath the saddle in vivo in the standing horse and in vitro on a wooden horse. They reported that, in order to obtain a consistent and repeatable measurement of the pressure applied to the equine back, it was necessary to position the sensor carefully and consistently over time relative to both the horse and the saddle. The FSA device is a useful tool in the development of a new equine saddle pad. However, it is susceptible to "biological noise" (horse) and operator-induced errors (Pullin et al. 1996). The Pliance system was found to be valid and reliable for measuring forces but only when the measurement device was not replaced (de Cocq et al. 2009). Werner et al. (2002) reported that the Pliance system was suitable for assessing the weight bearing surface and the pressure distribution under the saddle. The device provided valid results, but was only reliable in highly-standardized conditions since a high variation in pressure pattern occurred if the mat was slightly moved. Further technical improvement may be necessary (de Cocq et al. 2006).

Due to the presence of biological variables in the pressure measurement process compliance with a precise scientific methodology is needed. In order to obtain valid and repeatable data it is necessary to place sensors in the same anatomical region of the horse's back, to keep the same position of the horse and rider(s) (static and dynamic situations) during recording of the data, and to calibrate the device preferably between every measurement.

\section{Calibration of the system}

Pressure map calibration and establishing a system's zero base line is one of the factors necessary to obtain objective data and to enable a comparison to findings by other authors. Pullin et al. (1996) presented a guideline for system calibration that documents any observed and potential areas of error within the system that would affect objectivity of data collection. The most commonly used calibration is placing the pressure mat in a pneumatic test rig. A series of readings from the mat at different pressures, in both inclining and a declining pressure ranges, is assessed. Moreover re-calibration of the Pliance pressure mat is recommended by the manufacturer every two to three months (von Peinen et al. 2010). For the FSA system, the manufacturer (VERG, Inc.) recommends re-calibration of a new mat after 50 uses and after 200 uses for an older mat. Recalibration is necessary because the sensitivity of the sensors changes during use over time, especially in new sensors (de Cocq et al. 2006).

Not all sensors record the same pressure when subjected to the same loading. A problem can occur if the mat is slightly moved, especially when the same sensors can be used for measurements in different areas (de Cocq et al. 2006). This 
shift may be limited but not totally eliminated. Latif et al. 2010 observed a displacement of the pressure sensitive mat during trot of $<1.5 \mathrm{~cm}$. The method used to evaluate displacement, if indicated in the study, varies among individual authors depending on the type of equipment used and on the number of applications assessed. Jeffcott et al. (1999) determined the validity of saddle pressure measurement calibration with the help of a pneumatic test rig. Therefore they placed the mat together with an air-pressurised bag between two rigid surfaces. The calibration process was performed by increasing the pressure in steps of $10 \mathrm{mmHg}$ from 0 to 300 $\mathrm{mmHg}$. Then they repeated the calibration with decreasing pressures from 300 to $0 \mathrm{mmHg}$.

In the studies carried out by Byström et al. (2010), Clayłon et al. (2010), and de Coca et al. (2006) the mat was calibrated prior to each data collection session or at the beginning of every measurement day, respectively. Geutjens et al. (2008) also calibrated each half of the pressure mat prior to the start of data collection. The software used calibrated each sensor individually. Wesley (2006) calibrated the pressure mat with the manufacturer's calibration rig. Because pressures greater than the range of this rig were experienced in preliminary testing, an in-house calibration rig was constructed.

\section{Measured parameters}

Measured parameters can be divided based on the type of tasks investigated (von Peinen et al. 2010). Mean and maximum values (pressure, force) are used to determine the impact on the equine back. Total force is a variable for the assessment of the influence of the rider's body weight. Mean pressure gradient and pressure distribution are used for the identification of changes in dynamic loads in a movement cycle. These changes are also expressed by trajectory and amplitude of deviations of the COP (centre of pressure).

The influence of the shape and material of the saddle, pad, and blanket on the loading of the horse's back

A saddle is a rigid structure that connects two dynamic systems - the rider and its horse. The fit and the position of the saddle are basic factors affecting the interaction between these systems. Moreover the interaction between these systems significantly affects the movement of the horse (Harman 1994). The basic performance characteristics of the saddle (shock absorption and cushioning, low weight, prevention of saddle pad shift etc.) are easy to identify but very difficult to measure (Garber et al. 1978).

Saddles differ in a number of parameters, especially in the length and width of the tree, the padding surface, and the angle of the lateral parts of the tree. Studies that use pressure measurement systems for contact pressure measurements mainly aim to investigate the influence of the above mentioned saddle-parameters on the amplitude of the load. Meschan et al. (2007) used a pressure mapping mat to assess the influence of the width of the saddle tree on the pressure distribution beneath the saddle. The authors reported that the width of the tree had influence on pressure distribution between the saddle and the horse's back. The load measured beneath poorly fitting saddles was distributed over a smaller area than beneath properly fitting saddles.

The comparison of two different saddle products was assessed by Werner et al. (2002). Differences between the saddles were found mainly in the standing horse. The saddle cushion should distribute pressure evenly over the back of the horse and create a bridge connecting the anterior and posterior parts of the saddle with reduced pressure in the middle.

Latif et al. (2010) evaluated the influence of different saddle types (normal tree, treeless, flexible tree) on the longitudinal pressure distribution. At canter and gallop, all three saddle types were mainly loaded in the cranial part of the pressure picture. At trot, high peak pressures were observed in the caudal part of the pressure picture. These pressures reached the threshold value that is related to back pain in horses.

Frühwirth et al. (2004) evaluated pressure distribution beneath an English saddle in different gaits. The maximum total force increased with the velocity of movement (from walk to canter). Winkelmayr et al. (2006) found that the load beneath a side saddle in comparison to an English saddle was asymmetric and influenced the horse's back movement. A combination of both riding styles (both saddles) is suitable for changing the load distribution on the back of horses affected by back pain.

An important factor that can influence the amplitude of the contact load is placing other materials between the saddle and the horse's back such as a saddle pad and a blanket, or adding clamping elements such as a girth strap. Wesley (2006) defined an equine saddle pad as a space filler between the saddle and a horse's back.

On the one hand adding a saddle pad beneath a badly-fitted saddle can increase the pressure on a horse's back but on the other hand a properly fitted saddle with a pad can serve as a shock absorber (Harman 1994).

Kotschwar et al. (2010a) evaluated the influence of different saddle pads on the forces acting on the horse's back and on pressure distribution. For comparison, measurements were made without a saddle pad. While correct strapping of the saddle significantly reduces the size of operating load, none of the saddle pads had a significant influence on the maximum overall force compared to measurements without a saddle pad.

The effect of the long-term use of different saddle pads on the changes in the load of on a horse's back was assessed by Wesley (2006). Pressures from the saddle and rider were mainly distributed in the shape of the saddle bars with peak pressures concentrated in the area of the withers. During canter the pressure distribution was asymmetrical comparing data derived from the right and the left side of the pressure measuring mat. Kotschwar et al. (2010b) did not find a significant difference in maximum overall force with or without a saddle pad. Improvement of fit of an excessively-wide saddle using a saddle pad needs to be evaluated individually for each horse.

A comparison of total force and localized pressure on horses' withers with three saddle blanket styles during standing and 


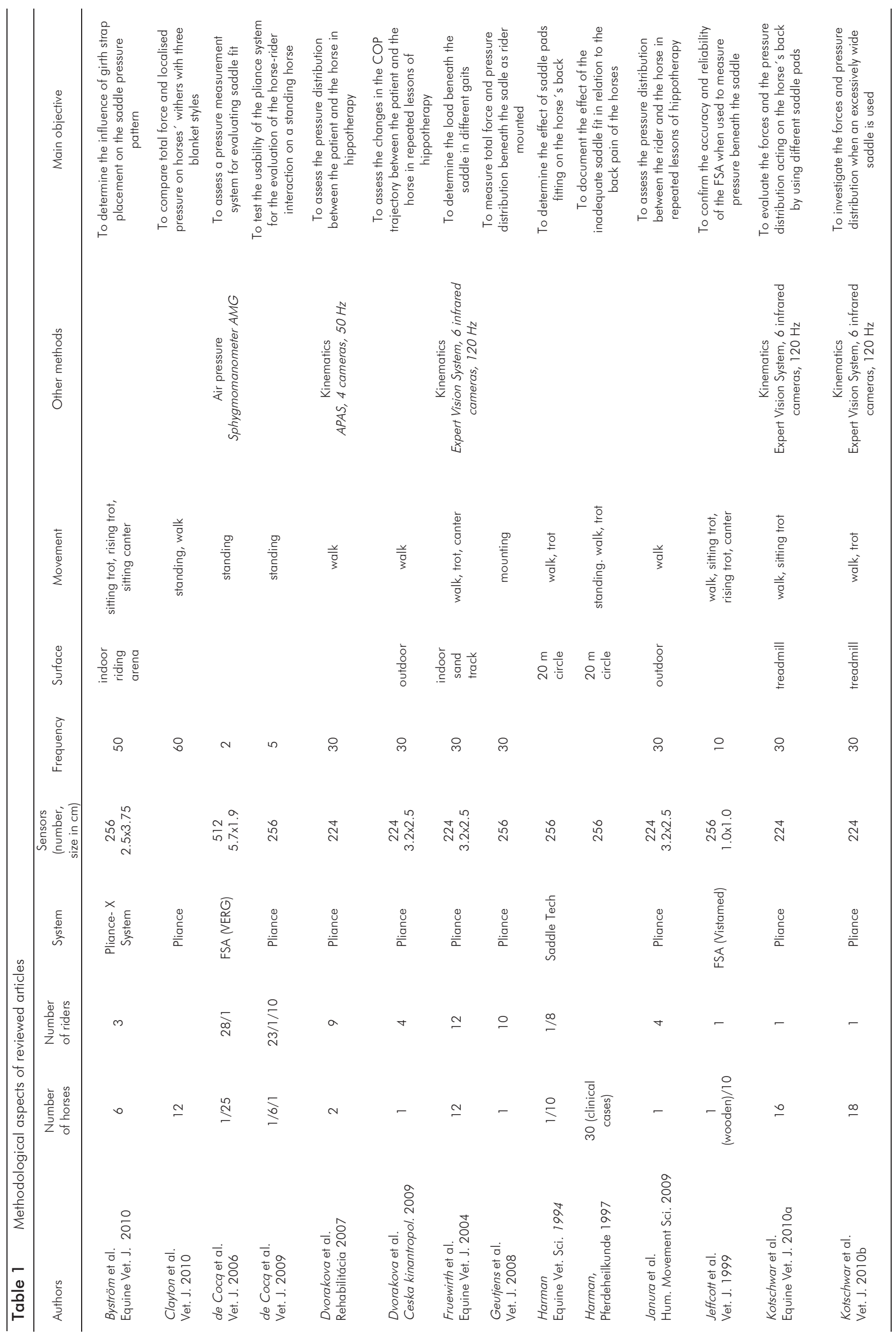




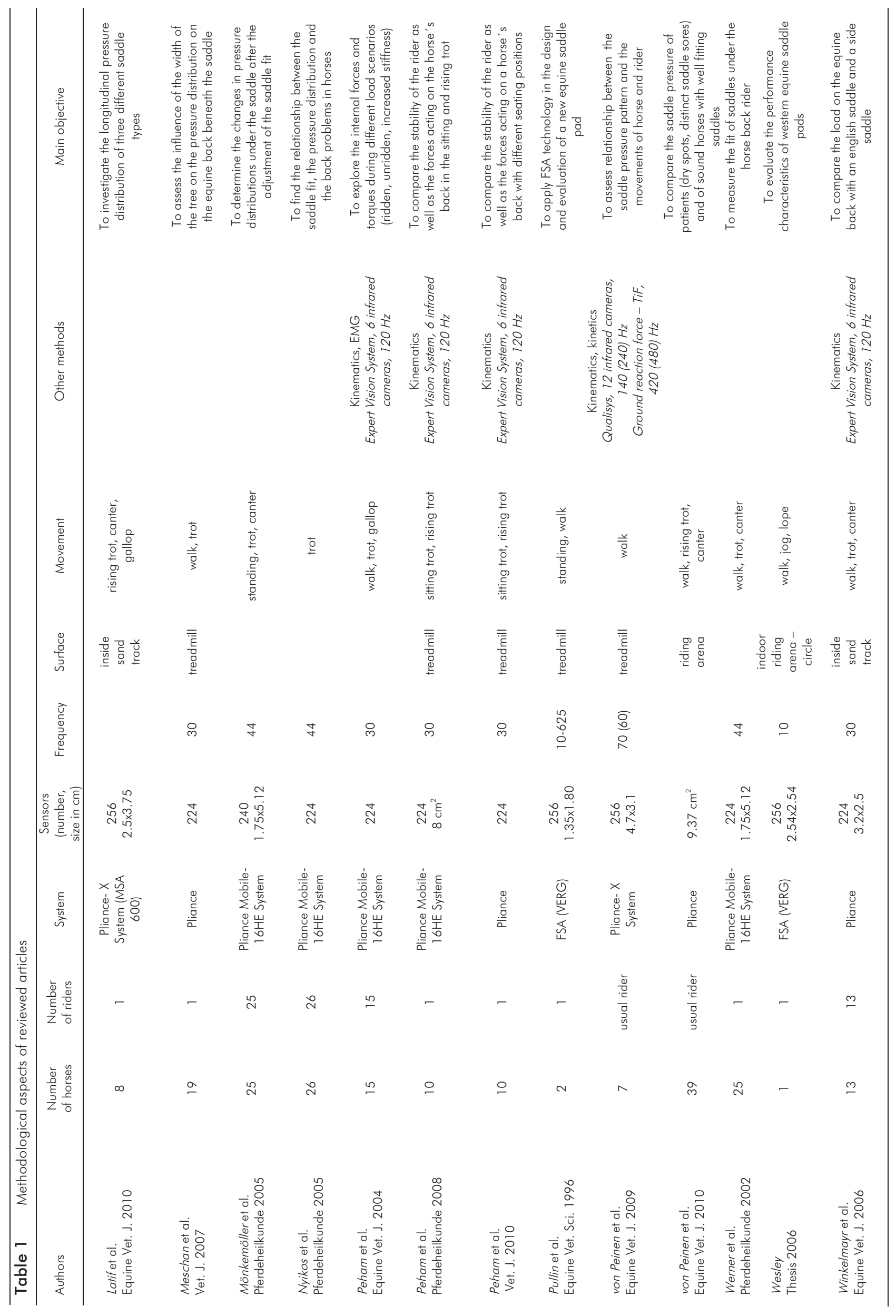


walk was carried out by Clayton et al. (2010). The results indicated that a certain style of saddle blanket significantly affects the size of force and pressure on the horse's withers.

Byström et al. (2010) evaluated the influence of the girth strap placement and panel flocking material on the saddle pressure pattern. Three combinations of different parameters (wool or foam panels and traditional girthing, wool panel, a $\mathrm{n}$ v-system girthing) were used. Results revealed that the type of flocking material as well as the girthing played an important role considering the proper fit of a saddle.

The influence of saddle fit on the load on the horse's back (back pain)

A poorly-fitted saddle is one of the main causes for back problems in horses. Horses can sustain tourniquet pressures, severely altering the capillary pressure of the skin on their extremities, of up to $600 \mathrm{mmHg}(80 \mathrm{kPa})$ for two hours before signs of local hypoxia and damage become evident (Scott et al. 1979). Pressures under the saddle often exceed the capillary closure pressure of $4.7 \mathrm{kPa}$, a condition which is known to cause ischemic necrosis in humans (Harman 1994).

The amplitude of pressure, used as a criterion for the proper fit of a saddle, varies between the individual authors. Harman (1997) mentioned that saddle pressures over $20 \mathrm{kPa}$ indicate a poor-fitting saddle. Werner (2002) defined $30 \mathrm{kPa}$ as an upper tolerated maximal pressure value in relation to back pain symptoms. In their study Clayton et al. (2010) determined that areas with pressures $>4 \mathrm{kPa}$ are related to back problems, since $4 \mathrm{kPa}$ is known to be the minimal required pressure to inhibit capillary blood flow.

Saddles creating pressures greater than the capillary closure pressure in the skin and muscles cause inflammation and pain, leading to performance problems (Harman 1997). Symptoms caused by back pain include reluctance to move when ridden and stiffness in lateral bending and dorso-ventral flexion. Significant correlations could be found between pressure values, back problems and saddle fit. The pressure tolerance was lower in the lumbar area than in the withers (Nyikos et al. 2005). Von Peinen et al. (2010) assessed differences in pressure distribution at the withers of healthy horses and patients suffering from dry spots, and saddle sores. During all gaits, mean pressure value differed between the groups. Lowest values were measured in healthy horses.

It is important to monitor long-term impact of saddle fit on back problems in horses. The use of a poorly-fitting saddle after treatment of back problems is likely to cause these problems to reoccur (Harman 1999). Mönkemöller et al. (2005) investigated the relationship between adjustment of saddle settings and back pain in horses. Results of the clinical examination revealed a significant positive effect due to the improved saddle fit regarding the reduction of back pain at least 12 weeks after the adjustment was done.

Not all horses are equally sensitive to excessive stress (Jeffcott 1980). Different breeds vary in the thickness of the skin (Sneddon et al. 2008). Therefore it is necessary to take the breed of a horse in consideration when evaluating the influence of pressures applied to the equine back.

Another point of interest that should be focused on is the use of data obtained from pressure mats for creating a model for the load applied to the equine back. These models will help to determine the impact of different parameters (morphology, type) on the load amplitude acting on the equine back. Peham and Schobesberger (2004) used this procedure simulating different conditions (ridden/unridden, localized increased stiffness) in order to understand the etiology and pathogenesis of equine back problems.

\section{Interaction between the horse and its rider}

The rider has a crucial influence on the biomechanical load acting on the horse. The main mechanical effect is quantified by his/her mass and is derived from gravity forces. The total force transmitted via the saddle pad during walk is closely correlated to the rider's body mass. The correlation coefficient between total pressure and mass of the rider, calculated in selected studies, was high: $r=0.98$ (Jeffcott et al. 1999) and $r=0.96$ (de Cocq et al. 2006).

The style of riding and the rider's movements have influence on the saddle pressure pattern (de Cocq et al. 2009, Peham et al. 2010). The analysis of the saddle force of six selected sections on the horse's back showed a clear association between the rider's and horse's movements (von Peinen et al. 2009). The changes in the forces were clearly related to the movement of the horse (front limbs, lateral flexion of the spine, axial rotation, and lateral bending of the back).

The equability and stability of the seat is crucial for communication between horse and rider. Peham et al. (2010) evaluated the influence of different seating positions during trot on the rider's stability as well as the forces acting on the horse's back. The maximum force during trot indicated that the acting gravitational acceleration was greater than $2 \mathrm{~g}$. The rider was most stable in the two-point seat while transferring the lowest load on the horse's back. The influence of an experienced rider on the stability of the forces acting on the horse's back during sitting trot and during posting trot on a treadmill was assessed by Peham et al. (2008). The posting trot was found to be more stable and less stressful for the horse's back compared to the sitting trot. Repetitive patterns of pressure act on the horse's back that increase simultaneously with the increase in momentum, weight, and instability of the rider (Wesley 2006).

Permanent incorrect rider's posture, state of tension, and instability of the rider may harm the horse and lead to various diseases and disorders of the muscular skeletal system (de Coca et al. 2009). Therefore, when comparing results of individual studies it is important to consider whether horses were measured ridden by their usual rider (Früwirth et al. 2004, Harmann 1994, Mönkemöller et al. 2005, Nyikos et al. 2005, Peham et al. 2004 etc.) or if an independent rider was used for the entire study population (Kotschwar et al. 2010 a und b, Latif et al. 2010, Meschan et al. 2007, Peham et al. 2008, etc.).

Therefore the influence of the rider on the measured data can be minimized. (Kotschwar et al. 2010b). However the good 
"knowledge" of the horse is important to choose a uniform speed for each horse in all gaits.

Devices for measurements of amplitude and layout of contact pressures have recently been used in hippotherapy. In contrast to typical horseback riding, in hippotherapy the pressure readings are taken directly between the patient's body and horse's back, which simplifies processing of the collected data. Sitting positions on a horse are different in horseback riding and hippotherapy (pelvic position; "active" vs. "passive" seat), which is reflected in the different COP trajectories (Dvorakova et al. 2007, 2009).

The disparities between parameters of the COP movement (range in mediolateral direction, area) could be reduced with the increased hippotherapy experience of the patient (Dvorakova et al. 2009). On the contrary, pressures between the patient's body and the horse's back increased with the number of hippotherapy lessons (Janura et al. 2009).

\section{Limits of the studies}

Establishment of the zero base value

Differences between the studies can be caused by zeroing the baselines. This was accomplished in two different ways; One way was to reset the mat to zero before placing the saddle and tightening the girth (Latif et al. 2010, von Peinen et al. 2009 and 2010), the other more common way was to reset the pad to zero after saddling and tightening the girth (Früwirth et al. 2004, Kotschwar et al. 2010 a and b, Meschan et al. 2007, Peham et al. 2010, Winkelmayr et al. 2006).

Due to the missing saddle in hippotherapy measurements the above discussed problem could be neglected. In this case the pad was reset to zero after placing the pad on the horse (Janura et al. 2009).

\section{Speed of movement, and ground surfaces}

Both the speed of the horse's movement and the nature of the ground on which the horse is moving can influence the motion of the horse. The speed of the horse may influence its motion pattern and tension of its back muscles (McLaughlin et al. 1996, Robert et al. 2001). Treadmill locomotion, as well as different ground surfaces, change the horse's movement pattern (Buchner et al. 1994). Even small changes $(0.1 \mathrm{~m} / \mathrm{s})$ in the speed of locomotion are known to alter pressure parameters (Bogisch et al. 2008). Byström et al. (2010) assessed the influence of girth strap placement on the saddle pressure pattern. They found that speed significantly effected the total force and the peak pressure. Curves showing the total saddle force of a horse during walk on a treadmill at constant speed and on a sand track at undefined velocities are differently shaped (von Peinen et al. 2009).

The deciding factor for setting the speed of the movement on a treadmill is the rider, similar to the conditions in an arena. In hippotherapy this is done by a horse-leader. In the study by Winkelmayr et al. (2006) the riders were asked to choose a uniform speed typical for each horse at all gaits. Similarly, a suitable speed for each horse was chosen, the moment the rider confirmed a rhythmical trot without the constant use of rider's aids (Meschan et al. 2007, Peham et al. 2010).

Chosen speeds differed among the measured horses. The most important factors for selecting the suitable speed are the individual morphologic parameters of each horse. In the current study it was not possible to evaluate every horse at the same speed due to the differences in size and breed. Therefore the treadmill speed was varied during training sessions (Kotschwar et al. 2010b).

Speed as well as the mode of setting the speed varies among the different studies. During walk speed ranges from 1.46 $\mathrm{m} / \mathrm{s}$ (von Peinen et al. 2009) to $1.67 \mathrm{~m} / \mathrm{s}$ (Kotschwar et al. 2010a) to $2.0 \mathrm{~m} / \mathrm{s}$ (Pullin et al. 1996). While trotting values mentioned by different authors reached $3.04 \mathrm{~m} / \mathrm{s}$ (Kotschwar et al. 2010a), 3.5m/s (Latif et al. 2010), $3.95 \mathrm{~m} / \mathrm{s}$ (Byström et al. 2010) respectively.

In most of the studies movement of the horse was measured on the long side of a riding arena or on the treadmill. Exceptions are the studies by Harman (1994, 1997) and Wesley (2006), where the horse moved on a circular path. This can influence the asymmetric pattern of movement and the changes in the amplitude and layout of the contact load (Hodgson and Rose 1994, Wesley 2006).

\section{Dividing the measured area, measured parameters}

Dividing the measured area allows detailed localization of the measured parameters. Therefore anatomical structures are used as landmarks. In the study by Pullin et al. (1996), the sensor pad was consistently placed along the centre of the vertebral column to ensure equal pressure mapping between left and right side. In most cases the mat was divided into two distinct halves, left and right (Dvorakova et al. 2009, Janura et al. 2010, Peham et al. 2010, Winkelmayr et al. 2006). These halves were further divided into two transverse halves during evaluation of pressures (Byström et al. 2010, de Coca et al. 2006, de Cocq et al. 2009, Geutjens et al. 2008) or three (front, mid, hind) parts (Latif et al. 2010, von Peinen et al. 2009).

In the studies by Meschan et al. (2007) and Kotschwar et al. $(2010 a, b)$ the left and the right halves of the pressure mat were additionally divided into transversal and longitudinal thirds.

Variables considered to be relevant for the assessment of saddle fit are different depending on the type of task. When interpreting the results, it is necessary to keep in mind that the reliability of individual parameters is different, e.g.: mean pressure is more reliable than maximum pressure (de Cocq et al. 2006).

One limitation of the above mentioned studies is that it is only possible to measure the normal force and not the shear force when using a pressure mat. Another critical point is that the shift of the saddle or the mat may cause a load, which can create pressure sores. 


\section{Conclusions}

The use of systems for pressure measurement between the rider's body and the equine back is a relatively new procedure. Presence of several biological systems (at least two, the horse and the rider) places increased demands on methodology of measurement.

Technical parameters of sensors need to fulfill an adequate degree of accuracy and repeatability; some problems might be caused by an incorrect calibration processes. Errors induced by biological systems and by their interactions are often difficult to identify as well as to quantify. Therefore, a proper approach to the interpretation of measured data is necessary, so one can provide an objective explanation for differences found, especially in dynamic situations (Holmes and Jeffcott 2010). Only then can the results obtained be considered as sufficiently valid.

The systems for measuring pressures can be used as a diagnostic device for prevention of problems caused by the use of an incorrect, or incorrectly-fitting, saddle. Significant correlations were found between pressure values, saddle fit, blanket style, saddle pad and back problems. A properly fitted saddle with a pad can serve as a shock absorber. The pressure distribution between the saddle and the horse's back is influenced by the width of the tree. Improvement of the fit of a saddle using a saddle pad needs to be considered individually for each horse. Incorrect rider's posture, state of tension, and instability of the rider may result in back problems for the horse.

Using the systems in hippotherapy, showed that pressure measured between the subject's (patient's) body and the horse's back increased as a result of growing confidence of the subjects gained over an increasing number of hippotherapy lessons. Further research should focus in particular on:

- finding a possibility to place sensors (saddle map) into the contact area of the saddle;

- developing a device capable of minimizing the noise generated during data collection;

- increasing sensor sensitivity, so that reliable data can be obtained even in situations where only low pressures are generated;

- establishing standards for determination of the "normal pattern" of the pressure distribution;

- including individual parameters of the horse and its rider into the overall assessment;

- utilizing obtained data for biomechanical modeling of contact surfaces and their interactions;

- synchronization of different systems (kinematic analysis) for a complex data analysis;

- enlarging the pressure mat area, which would enhance possibilities of pressure measurements in hippotherapy, where the patient's position on the horse can be very different from regular horseback riding.

\section{Acknowledgements}

This paper was supported by research grants of the Ministry of Education, Youth and Sport of the Czech Republic (No.
MSM 6198959221) and Faculty of Physical Culture, Palacky University Olomouc (No. FTK_2010_023).

\section{References}

Bogisch S., von Peinen K., Wiestner T., Roepstorff L., van Weeren R. and Weishaupt M. A. (2008) Influence of speed on the horse-rider interaction and resulting saddle forces at walk and trot. In: ICEL 6 Abstracts. Cabourg, Ecole Nationale Vétérinaire d'Alfort, 22

Buchner H. H., Savelberg H. H., Schamhardt H. C., Merkens H. W. and Barneveld A. (1994) Kinematics of treadmill versus overground locomotion in horses. Vet. Quart., Suppl. 2, S87-S90

Byström A., Stalfelt A., Egenvall A., von Peinen K., Morgan K. and Roepstorff L. (2010) Influence of girth strap placement and panel flocking material on the saddle pressure pattern during riding of horses. Equine Vet. J., Suppl. 38, 502-509

Clayton H. M., Kaiser L. J. and Nauwelaerts S. (2010) Pressure on the horse's withers with three styles of blanket. Vet. J. 184, 52-55

de Coca P., Clayton H. M., Terada K., Muller M. and van Leeuwen J. L. (2009) Usability of normal force distribution measurements to evaluate asymmetrical loading of the back of the horse and different rider positions on a standing horse. Vet. J. 181, 266-273

de Cocq P., van Weeren P. R. and Back W. (2006) Saddle pressure measuring: Validity, reliability and power to discriminate between different saddle-fits. Vet. J. 172, 265-273

Dvorakova T., Janura M., Svoboda Z. and Elfmark M. (2009) The analysis of the center of pressure (COP) movement on the contact area between rider and the horse in hippotherapy - pilot study [in Czech]. Ces. kinantropol. 13, 16-22

Dvorakova T., Peham C., Elfmark M. and Janura M. (2007) Motion dialog between horse and its rider - the contribution to the practice [in Czech]. Rehabilitacia 44, 137-141

Ferguson-Pell M. W., Bell F. and Evans J. H. (1976) Interface pressure sensors: existing devices, their suitability and limitations. In: Bedsore Biomechanics (eds. Kenedi R., Cowden J.M. and Scales J.T.). University Park Press, Baltimore, MD, 189-197

Ferguson-Pell M. W., Reddy N. P., Stewart S. F. C., Palmieri V. and Cochran G. V. B. (1985) Measurement of physical parameters at the patient support interface. In: Biomechanical Measurement in Orthopaedic Practice (eds. Whittle M. and Harris D.). Clarendon Press, Oxford, 133-44

Frühwirth B., Peham C., Scheidl M. and Schobesberger H. (2004) Evaluation of pressure distribution under an English saddle at walk, trot and canter. Equine Vet. J. 36, 754-757

Garber S. L., Krouskop T. A. and Carter R. E. (1978) A system for clinically evaluating wheelchair pressure-relief cushions. Am. J. Occup. Ther. 32, 565-570

Geutiens C. A., Clayton H. M. and Kaiser L. J. (2008) Forces and pressures beneath the saddle during mounting from the ground and from a raised mounting platform. Vet. J. 175, 332-337

Harman J. C. (1994) Practical use of a computerized saddle pressure measuring device to determine the effects of saddle pads on the horse's back. J. Equine Vet. Sci. 14, 606-611

Harman J. C. (1997) Measurement of the pressures exerted by saddles on the horse's back using a computerized pressure measuring device. Pferdeheilkunde 13, 129-134

Harman J. C. (1999) Tack and saddle fit. Vet. Clin. North Am. Equine Pract. 15, 247-261

Hodgson D. R. and Rose R. J. (1994) The athletic horse: principles and practice of equine sports medicine. W. B. Saunders Company, Philadelphia, PA

Holmes M. and Jeffcott L. (2010) Equitation, science, rider effect, saddle and back problems in horses: Can technology provide the answer? Vet. J. 184, 5-6

Janura M., Peham C., Dvorakova T. and Elfmark M. (2009) An assessment of the pressure distribution exerted by a rider on the back of a horse during hippotherapy. Hum. Mov. Sci. 28, 387-393

Jeffcott L. B. (1980) Disorders of the thoracolumbar spine of the horse. A survey of 443 cases. Equine Vet. J. 12, 197-209 
Jeffcott L. B., Holmes M. A. and Townsend H. G. G. (1999) Validity of saddle pressure measurements using force-sensing array technology - preliminary studies. Vet. J. 158, 113-119

Kotschwar A. B., Baltacis A. and Peham C. (2010a) The effects of different saddle pads on forces and pressure distribution beneath a fitting saddle. Equine Vet. J. 42, 114-118

Kotschwar A. B., Baltacis A. and Peham C. (2010b) The influence of different saddle pads on force and pressure changes beneath saddles with excessively wide trees. Vet. J. 184, 322-325

Krouskop T. A., Noble P. C., Garber S. L. and Spencer W. A. (1983) The effectiveness of preventive management in reducing the occurrence of pressure sores. J. Rehabil. R. D. 20, 74-78

Latif S. N., von Peinen K., Wiestner T., Bitschnau C., Renk B. and Weishaupt M. A. (2010) Saddle pressure patterns of three different training saddles (normal tree, flexible tree, treeless) in thoroughbred racehorses at trot and gallop. Equine Vet. J., Suppl. 38, 630636

McLaughlin R. M., Gaughan E. M., Roush K. and Skaggs C. (1996) Effects of subject velocity on ground reaction force measurements and stance times in clinically normal horses at the walk and trot. Am. J. Vet. Res. 57, 7-11

Meschan E. M., Peham C., Schobesberger H. and Licka T. F. (2007) The influence of the width of the saddle tree on the forces and the pressure distribution under the saddle. Vet. J. 173, 578-584

Mönkemöller S., Keel R., Hambsch D., Muller J., Kalpen A., Geuder M., Aver J. A. and von Rechenberg B. (2005) Pliance Mobile16HE: A study about pressure measurements under the saddle after the adjustment of the saddle fit. Pferdeheilkunde 21, 102 114

Nyikos S., Werner D., Müller J. A., Buess C., Kee, R., Kalpen, A., Vontobel H. D. and von Rechenberg B. (2005) Measurements of saddle pressure in conjunction with back problems in horses. Pferdeheilkunde 21, 187-198

Peham C., Hofmann A., Molsner J., Borkenhagen B., Kuhnke S. and Baltacis A. (2008) Forces acting on the horses back and the stability of the rider in sitting and rising trot - a comparison. Pferdeheilkunde 24, 337-342

Peham C., Kotschwar A.B., Borkenhagen B., Kuhnke S., Molsner J. and Baltacis A. (2010) A comparison of forces acting on the horse's back and the stability of the rider's seat in different positions at the trot. Vet. J. 184, 56-59

Peham C., Licka T., Schobesberger H. and Meschan E. (2004) Influence of the rider on the variability of the equine gait. Hum. Mov. Sci. 23, 663-671

Peham C. and Schobesberger H. (2004) Influence of the load of a rider or of a region with increased stiffness on the equine back: a modelling study. Equine Vet. J. 36, 703-705

Pullin J. G., Collier M. A., Durham C. M. and Miller R. K. (1996) Use of force sensing array technology in the development of a new equine saddle pad: static and dynamic evaluations and technical considerations. J. Equine Vet. Sci. 16, 207-216
Robert C., Audigié F., Valette J. P., Pourcelot P. and Denoix J. M. (2001) Effects of treadmill speed on the mechanics of the back in the trotting saddlehorse. Equine Vet. J. 33, Suppl., 154-159

Schöllhorn W., Peham C., Licka T. and Scheidl M. (2006) A pattern recognition approach for the quantification of horse and rider interactions. Equine Vet. J. Suppl. 36, 400-405

Scott E. A., Riebold T. W., Lamar A. M., Wolz G. S., Sandier G. A. and Thompson L. R. (1979) Effect of pneumatic tourniquet application to the distal extremities of the horse: blood gas, serum electrolyte, osmolality, and hematologic alterations. Am. J. Vet. Res. 40, 1078-1081

Sneddon J. C., Ritruechai P., de Yanes G. S. and Howard C. V. (2008) Seasonal influences on quantitative changes in sweatassociate anatomy in native and thoroughbred horses. Vet. Dermatol. 19, 163-173

von Peinen K., Wiestner T., Bogisch S., Roepstorff L., van Weeren P. R. and Weishaupt M. A. (2009) Relationship between the forces acting on the horse's back and the movements of rider and horse while walking on a treadmill. Equine Vet. J. 41, 285-291

von Peinen K., Wiestner T., von Rechenberg B. and Weishaupt M. A. (2010) Relationship between saddle pressure measurements and clinical signs of saddle soreness at the withers. Equine Vet. J., Suppl. 38, 650-653

Werner D., Nyikos S., Kalpen A., Geuder M., Haas C., Vontobel H.D., Aver J. A. and von Rechenberg B. (2002) Pressure measurements under the saddle: A study using an electronic saddle mat system (Novel GmbH). Pferdeheilkunde 18, 125-140

Wesley E. D. (2006) Performance evaluation of saddle pads. MA Thesis. Kansas State University, Manhattan, KS

Winkelmayr B., Peham C., Frühwirth B., Licka T. and Scheidl M. (2006) Evaluation of the force acting on the back of the horse with an English saddle and a side saddle at walk, trot and canter. Equine Vet. J. Suppl. 36, 406-410

Prof. RNDr. Miroslav Janura

Department of Natural Sciences in Kinanthropology

Faculty of Physical Culture

Palacky University Olomouc

tr. Miru 115

77171 Olomouc

Czech Republic

miroslav.janura@upol.cz 